\title{
Programa Bolsa Família: nova institucionalidade no campo da política social brasileira?
}

\author{
Mônica de Castro Maia Senna \\ Luciene Burlandy \\ Universidade Federal Fluminense (UFF)
}

Giselle Lavinas Monnerat

Universidade do Estado do Rio de Janeiro (UERJ)

\author{
Vanessa Schottz \\ Programa Direito à Segurança Alimentar e Agroecologia da \\ Federação de Órgãos para Assistência Social e Educacional (FASE) \\ Rosana Magalhães \\ Escola Nacional de Saúde Pública Sergio Arouca, FIOCRUZ
}

\section{Programa Bolsa Família: nova institucionalidade no campo da política social brasileira?}

Resumo: O Programa Bolsa Família foi implantado pelo governo federal brasileiro em outubro de 2003 com a perspectiva de combater a pobreza e a fome no país e promover inovações no padrão histórico de intervenção pública na área social. Esse artigo analisa o desenho do Programa, buscando identificar possíveis inflexões nele contidas, a partir dos seguintes eixos: foco e condições de acesso, condicionalidades, descentralização, intersetorialidade e controle social. O estudo tomou por referência a legislação e documentos oficiais, apontando limites e potencialidades à sua operacionalização. Dentre as mudanças pretendidas, destaca-se o complexo esforço de ampliação da arena decisória, de forma a incorporar diferentes níveis e esferas governamentais e a sociedade civil. Por outro lado, observam-se limites dados pela restrição dos mecanismos de focalização da clientela e pela indefinição de aspectos relativos ao controle social e à gestão compartilhada. A questão das condicionalidades configura uma polêmica central, merecendo estudos mais aprofundados. Palavras-chave: política social, combate à pobreza, programas de transferência de renda, Bolsa Família.

\section{The Family Grant Program: New Institutionalism in Brazilian Social Policy}

Abstract: The Family Grant Program was established by the Brazilian federal government in October 2003 to fight poverty and hunger and promote innovations in government social intervention. This article analyzes the program's design and tries to identify possible inflections contained within it, based on the following focus: conditions of access, conditionalities, decentralization, intersectoral factors and social control. The study analyzed official documents and legislation, and indicates the limits and potential for their operationalization. The changes planned are highlighted by the complex effort to expand the decision-making arena, in order to incorporate different government levels and spheres as well as civil society. Limitations were noted that were created by the restrictive mechanisms for the focalization of clientele and by the lack of definition of factors related to social control and shared management. The question of conditionalities is a central problem that deserves greater study.

Key words: social policy, fighting poverty, income transfer programs, Family Grant. 


\section{Introdução}

Este artigo tem como objetivo analisar o desenho do Programa Bolsa Família (PBF), enfocando seus objetivos e estratégias operacionais. Interessa entender possíveis alterações que o Programa tem provocado no padrão clássico de intervenção do Estado brasileiro no campo das políticas sociais, especialmente no que se refere às políticas de combate à fome e à pobreza.

Foram destacados alguns dos principais aspectos contidos na estrutura organizacional do PBF, a saber: foco e condições de acesso ao Programa - englobando aqui os critérios de inclusão e mecanismos de seleção; condicionalidades; descentralização e intersetorialidade; e controle social.

$\mathrm{O}$ estudo de documentos e o acompanhamento da produção da legislação específica sobre o Bolsa Família, além da participação em eventos oficiais e seminários acadêmicos relativos ao Programa, foram os principais procedimentos metodológicos para a coleta de dados e informações que nortearam a discussão empreendida nesse artigo.

Entende-se aqui que o formato de uma dada política ou programa social é resultante de um complexo processo de intermediação de interesses, representados sob as mais variadas formas organizacionais e com diferentes graus de poder de influência na agenda governamental. Expressa, desse modo, uma opção política, construída sob certas condições materiais, a partir dos embates e alianças forjados por atores sociais diversos com capacidades também distintas de interferência no processo decisório de formulação de políticas públicas.

\section{Contexto de emergência dos programas de transferência de renda no Brasil}

As recentes transformações que vêm se operando no interior das economias mundiais, com o crescimento do desemprego e a aparição de novas formas e/ou agudização da pobreza, associados à chamada crise do Welfare State têm trazido à tona o debate acerca dos limites dos tradicionais programas sociais em responder às crescentes demandas sociais, impondo, assim, novos dilemas para a intervenção pública.

No Brasil, o tema da pobreza e destituição social vem assumindo lugar de destaque na agenda pública nas últimas décadas, não só em face do número alarmante de pobres como também pela centralidade adquirida pela discussão em torno da capacidade estatal em promover maiores níveis de eqüidade e justiça social.

Inflexões no padrão clássico das políticas sociais brasileiras se fazem sentir a partir de meados da década de 1980, no contexto de redemocratização do país. É nesse momento que ganham fôlego as críticas ao caráter altamente centralizado, burocratizado, fragmentado, privativista, excludente e de baixas eficácia e eficiência social que tem marcado as intervenções públicas neste campo. Dois traços característicos da política social brasileira vêm se destacando enquanto questões-chave a serem enfrentadas: a) os segmentos pobres são os que tradicionalmente têm maiores dificuldades de acessar os bens e serviços sociais, contribuindo para a persistência da desigualdade social; e b) a falta de interação entre os diferentes setores de governo, entre governo e sociedade e a conseqüente dificuldade de coordenação das ações desenvolvidas.

Na década de 1990, são adotadas estratégias institucionais destinadas a garantir que os programas sociais atinjam os segmentos mais vulneráveis. No campo das políticas de combate à pobreza strictu senso, algumas inflexões vêm sendo produzidas, e é nesse contexto que os programas de transferência de renda para famílias pobres têm despertado grande interesse analítico.

As origens de tais programas remontam a iniciativas locais, sobretudo no Distrito Federal e em municípios como Vitória (no Espírito Santo), Campinas e Ribeirão Preto (em São Paulo), objetivando combater a pobreza, sobretudo através da eliminação do trabalho infantil e do aumento do nível de escolaridade de crianças e adolescentes. Trata-se de experiências bastante diversas no que se refere a critérios de seleção, valor do benefício e formas de operação, entre outros, compartilhando uma grande riqueza em termos de inovações institucionais (DRAIBE et al., 1998).

Influenciado por essas experiências, o governo federal adotou, a partir de 2001, programas de transferência de renda para famílias pobres, como o Bolsa Escola, vinculado ao Ministério da Educação e o Bolsa Alimentação, do Ministério da Saúde. Tais programas consistiam na complementação de renda às famílias, que, em contrapartida, assumiam uma agenda de compromissos, tais como a garantia de freqüência escolar mínima das crianças atendidas e a participação em determinadas ações de saúde pública.

Algumas avaliações a respeito dos programas brasileiros de garantia de renda mínima (PGRM) apontam a vantagem da transferência monetária direta na diminuição dos custos administrativos do programa e na redução da incidência de fraudes e desvios de recursos, além de permitir a liberdade de escolha dos produtos por parte dos beneficiários, quando comparada à clássica modalidade de distribuição do benefício in natura (LAVINAS, 2000). Ao mesmo tempo, os PGRMs têm como proposta promover a articulação com outras políticas e programas sociais, criando a possibilidade de, em tese, romper com a fragmentação típica das políticas sociais brasileiras e facilitar a adoção de ações intersetoriais. 
Cabe lembrar que desde o período da transição democrática a agenda de debate no campo da política social brasileira comporta uma série de temas que tratam das reformas necessárias à construção de uma nova institucionalidade pública, focando principalmente os desafios relativos à formulação e implementação de políticas e programas sociais. Nesse processo, a aposta fundamental é inovar tanto na formulação dos programas quanto na definição de estratégias de implementação capazes, assim, de provocar melhores resultados e maiores impactos sobre a pobreza e desigualdade social.

\section{O Programa Bolsa Família: focalização e condi- ções de acesso}

Apesar dos avanços obtidos na trajetória dos programas de transferência de renda na década de 1990, como uma estratégia de combate à fome e à pobreza, as ações governamentais nessa área foram ainda marcadas pela fragmentação e paralelismo. Com efeito, perpetuaram-se mecanismos de sobrefocalização dos beneficiários - ou seja, enquanto algumas famílias recebiam o Bolsa Escola e o Bolsa-Alimentação, outras famílias em igual condição de miséria não recebiam qualquer benefício - além da baixa cobertura e do frágil controle social.

$\mathrm{Na}$ tentativa de superar essas debilidades e consolidar uma estratégia nacional de transferência condicionada de renda, o governo federal instituiu, em outubro de 2003, o Programa Bolsa Família, reunindo quatro programas de transferência de renda anteriores - Bolsa Escola, Auxílio-Gás, Bolsa Alimentação e Cartão Alimentação - sob gestão unificada.

A unificação de tais programas, segundo a lei que criou o PBF, visa "melhorar a gestão e aumentar a efetividade do gasto social através da otimização e racionalização, ganhos de escala e facilidade da interlocução do Governo Federal com estados e municípios" (BRASIL, 2006).

Desde 2004, o PBF encontra-se vinculado ao então recém-criado Ministério de Desenvolvimento Social e Combate à Fome (MDS), mais especificamente à Secretaria Nacional de Renda de Cidadania (SENARC) e constitui uma das prioridades do Governo Federal para a área social.

Acompanhando as tendências das recentes políticas sociais, o PBF prioriza a família como unidade de intervenção, com o seu acesso voltado àquelas que se encontram em situação de pobreza ou de extrema pobreza. A linha de pobreza é estabelecida a partir da renda familiar, cujo valor é de, no máximo, R\$ 120 per capita. O Programa tem como população-alvo dois grupos. Ao primeiro, pertencem as famílias com renda per capita abaixo de $\mathrm{R} \$ 60$ para as quais é concedido o benefício mensal fixo de R\$
50 , podendo esse valor ser acrescido de $\mathrm{R} \$ 15$ por cada gestante, nutriz, criança e adolescente, até o limite de R\$45. Nesse caso, o valor total do benefício não ultrapassaria $\mathrm{R} \$ 95$. No segundo grupo, estão as famílias com renda per capita entre $R \$ 60$ e $\mathrm{R} \$ 120$. Essas família têm direito ao benefício variável de R\$ 15 por cada gestante, nutriz, criança e adolescente, compondo um valor máximo de R $\$ 45$ (BRASIL, 2006). A lei prevê ainda que o valor do benefício do Programa Bolsa Família poderá ser complementado pelos estados, DF e municípios, dependendo do termo de cooperação firmado.

Merece relevo a velocidade de implementação do PBF, retratada pelos dados de cobertura. Em dezembro de 2003, o Programa atendia 3,6 milhões de famílias, passando para 6,5 milhões no mesmo mês do ano seguinte e, em dezembro de 2005, atingiu um total de 8,7 milhões. No início de 2006, o PBF já atingia a meta prevista de 11,1 milhões de famílias atendidas.

Sobre a focalização do Programa, um primeiro aspecto a considerar é o uso da renda monetária como critério único de seleção das famílias, o que é largamente criticado na literatura especializada. Com efeito, somente a renda não é suficiente para qualificar a pobreza, fenômeno multifacetado que engloba outras dimensões de vulnerabilidade social, tais como: saúde, esperança de vida, educação, saneamento e acesso a bens e serviços públicos, que vão além da privação de bens materiais (TOWSEND, 1993; SEN, 2001).

Ademais, a definição arbitrária de um valor per capita muito baixo tende a impossibilitar a inclusão de famílias que, apesar de situadas em uma faixa de renda um pouco acima do valor definido, encontramse também em situação de pobreza. Outro aspecto complicador refere-se à desvinculação deste corte ao salário mínimo ou a qualquer outro índice de reajuste deste valor, o que pode levar, a médio prazo, a tornar este critério cada vez mais restritivo. Vale dizer que nos programas de transferência de renda que antecederam o PBF, o corte de renda estava vinculado a frações do salário mínimo vigente.

Em verdade, uma das mais difíceis tarefas a ser enfrentada por programas focalizados como o PBF é a construção de critérios e mecanismos de seleção dos grupos sociais que serão ou não contemplados, de forma a considerar o conjunto de vulnerabilidades sociais a que esses segmentos estão expostos. Com efeito, os mecanismos capazes de promover a inclusão dos grupos que necessitam de uma dada política serão tão mais efetivos quanto sua capacidade de captar estas distintas vulnerabilidades (MAGALHÃES et al., 2004).

Um outro importante desafio relacionado aos programas sociais focalizados diz respeito à forma como se processa a seleção dos beneficiários. No caso do Programa Bolsa Família, esta seleção é realizada por meio do Cadastramento Único (Cad-Único) do governo Federal - instituído em 2001, ainda no governo 
de Fernando Henrique Cardoso - cujo objetivo é uniformizar as informações sobre possíveis beneficiários do PBF e demais programas sociais, propondo-se também a subsidiar o planejamento de políticas públicas dos diferentes níveis de governo.

Como vimos, um aspecto central do desenho do Programa Bolsa família é a focalização nas famílias pobres. Decerto, a formulação de programas sociais com foco na família e não exclusivamente no indivíduo faz parte do debate sobre o processo de reformas das políticas sociais desenvolvidas no país desde os anos 1980.

Num esforço para compreender as razões pelas quais ocorre a retomada da família como prioridade de intervenção nas duas últimas décadas, Carvalho (1997) argumenta que a abordagem sobre o tema família adquire novas especificidades em razão do reconhecimento de uma inequívoca situação de desemprego estrutural que afeta a já frágil capacidade das famílias enfrentarem os desafios de reprodução social de seus membros. Nesse sentido, são grandes as expectativas de se alcançar melhores resultados a partir da implementação de programas e políticas que considerem a família como sujeito importante no processo de proteção social. Dissemina-se, então, a idéia de que os programas sociais têm maior possibilidade de otimizar recursos quando passam a focar a família ao invés do indivíduo. Como defende Draibe (1997), a decisão de se tomar a família como unidade de intervenção está respaldada no argumento de que as políticas de proteção à família teriam maior potencial de impactar as condições de vida da população pobre.

Com base nestas preocupações e considerando as transformações recentes na configuração das famílias brasileiras, o PBF procura incorporar um conceito mais amplo de família, no qual se verifica uma tendência de rompimento com a idéia tradicional de família nuclear. Nesta direção, consta no artigo $2^{\circ}$, parágrafo $1^{\circ}$, da lei de criação do PBF a definição de família como uma "unidade nuclear, eventualmente ampliada por outros indivíduos que com ela possuam laços de parentesco ou afinidade, que forme um grupo doméstico, vivendo sob o mesmo teto e que se mantém pela contribuição de seus membros" (BRASIL, 2006).

Diferentemente dos programas de transferência de renda anteriores, que consideravam inelegíveis as famílias sem filhos, gestantes ou nutrizes, o Bolsa Família amplia, até certo ponto, seu escopo de atendimento, ao permitir o acesso desse tipo de família ao Programa. Importante salientar que se trata ainda de uma perspectiva restritiva, haja vista que o acesso das famílias sem filhos é somente permitido àquelas que estiverem em situação de pobreza extrema. Sobre este ponto, e conforme já mencionado, talvez o principal problema seja o baixo valor do corte de renda para pobreza extrema $(\mathrm{R} \$ 60)$, o que, na práti- ca, representa um grande risco de excluir muitas dessas famílias pobres.

Draibe et al. (1998), ao analisarem os programas de transferência de renda desenvolvidos nos anos 1990, assinalam que o foco na família foi a forma encontrada pelos formuladores de tais políticas para atingir seu principal público-alvo - crianças e adolescentes - e incluí-los em outras políticas, sobretudo a de educação, tornando pais e responsáveis meros intermediários neste processo. Se, de algum modo, tal análise pode ser transposta para o PBF, é necessário pensar em que medida a família é (ou não), na realidade, a unidade privilegiada de intervenção do Programa.

\section{Condicionalidades}

Seguindo a trajetória dos programas de transferência de renda no Brasil, o PBF define o cumprimento de algumas condicionalidades relacionadas às áreas de saúde e educação. A expectativa, segundo justificativa explicitada na legislação e documentos oficiais do Programa, é de que o cumprimento de condicionalidades tanto possibilite o acesso e a inserção da população pobre nos serviços sociais básicos como favoreça a interrupção do ciclo de reprodução da pobreza, configurando, assim, uma espécie de 'porta de saída' do Programa.

Em relação aos serviços de saúde, o PBF determina que gestantes, nutrizes e crianças de 0 a 6 anos sejam acompanhadas do ponto de vista nutricional, mantendo o esquema de vacinação em dia. Gestantes devem participar das consultas de pré e pós-natal e, assim como as mães de crianças de 0 a 6 anos, devem também participar das atividades educativas sobre saúde e nutrição. No que tange à educação, exige-se $85 \%$ de freqüência escolar das crianças e adolescentes na faixa entre 6 e 15 anos. O não cumprimento dessas condicionalidades implica no desligamento das famílias beneficiárias do Programa.

A legislação que define a gestão do acompanhamento das condicionalidades do Programa Bolsa Família é bastante minuciosa. Aqui, vale mencionar que as Portarias que tratam do assunto foram publicadas após denúncias $^{1}$ da grande imprensa no que diz respeito à condução das ações de controle das contrapartidas e à focalização do Programa.

Um primeiro aspecto a destacar é que embora a legislação recente seja clara quanto ao papel dos três níveis de governo na implementação das condicionalidades, é sobre o município que recai a maior parte das responsabilidades de oferta de serviços e de gestão do acompanhamento do cumprimento das obrigações das famílias beneficiárias.

As famílias que estiverem inadimplentes com relação ao cumprimento das condicionalidades estão sujeitas a uma série de sanções, que vão desde o bloqueio 
do benefício por 30 dias até o seu cancelamento. Tais regras podem criar, em verdade, um processo de exclusão que alarga ainda mais a distância entre o PBF e a lei de autoria do senador Eduardo Suplicy, recém aprovada no Congresso Nacional, que institui uma renda básica de cidadania universal e incondicional.

Além disso, a ausência de registro do resultado do acompanhamento das condicionalidades nos sistemas de informação, definidos pelos ministérios da educação e saúde, poderá também acarretar em bloqueio e perda do benefício, a critério do MDS. A legislação preserva as famílias de qualquer sanção somente quando ficar comprovado que o cumprimento das condicionalidades foi prejudicado em razão de problemas relativos à oferta de serviços por parte dos municípios.

Considerando que são prerrogativas dos municípios manter atualizado o sistema de informação e ofertar os serviços relativos às condicionalidades, pode-se imaginar que inúmeros problemas relativos às diferentes capacidades financeira e gerencial dos municípios interferirão no atendimento de tais requisições. Assim, não se pode deixar de levantar a possibilidade de que famílias sejam punidas em razão da incapacidade de muitos municípios em manter atualizado o repasse de informação para o MDS. Com efeito, a literatura que trata do processo recente de descentralização das políticas sociais no Brasil, dentre os quais se destaca o estudo de Arretche (2000), assinala que, em geral, os municípios brasileiros ainda têm apresentado muitas fragilidades na oferta de serviços de educação e saúde, comprometendo o processo de implementação das condicionalidades do PBF.

Um outro elemento a ser destacado é que, embora o município assine um termo de adesão ao Programa comprometendo-se a ofertar adequadamente os serviços básicos previstos nas condicionalidades, a legislação não prevê ações de responsabilização e punição para os municípios inadimplentes. Dessa forma, é sobre as famílias que recai, quase exclusivamente, a responsabilidade pelo cumprimento das condicionalidades.

Ademais, é preciso considerar que a perspectiva de inclusão social ao Bolsa Família está também ancorada na oferta de programas complementares (tais como programas de geração de emprego e renda, cursos profissionalizantes, microcrédito, compra de produção agrícola, oficinas de 'empreendedorismo' e apoio a iniciativas de economia solidária, entre outros) que, em tese, deve ser implementada de forma cooperativa entre os diferentes níveis de governo e com base na intersetorialidade das ações. Isso mostra o reconhecimento de que as ações básicas de saúde e educação isoladas não são suficientes para alcançar os objetivos do Programa.

Importante notar que, mesmo reconhecendo a relevância das ações complementares, estas não aparecem como obrigação dos entes federados e, portanto não constituem contrapartidas. Neste caso, não há definição de estratégias de implementação, o que demonstra total ausência de indução para ações que são, no plano dos discursos oficiais, consideradas porta de saída do Programa e da situação de pobreza.

Sobre essa questão, um outro aspecto importante a ser considerado é que, apesar do Programa optar pelo foco na família, a análise de sua estrutura organizacional demonstra que as exigências de contrapartidas estão previstas apenas para aqueles grupos tradicionalmente priorizados na política social, quais sejam: gestantes, nutrizes, crianças e adolescentes.

A principal polêmica em torno das condicionalidades do PBF aparece, por um lado, no reconhecimento de que as mesmas têm potencial de pressionar a demanda sobre os serviços de educação e saúde, o que, de certa forma, pode representar uma oportunidade ímpar para ampliar o acesso de um contingente importante da população aos circuitos de oferta de serviços sociais. Mas, por outro lado, como afirma Lavinas (2004), ao ser exigido o cumprimento de obrigatoriedades como condição para o exercício de um direito social, os próprios princípios de cidadania podem estar ameaçados.

Para os idealizadores do Bolsa Família, a exigência de condicionalidades constituiria uma forma de ampliar o exercício do direito à saúde e à educação, ainda incompletos entre nós. Entretanto, é preciso reconhecer que o alcance de tal objetivo exige a implementação de mecanismos consistentes de acompanhamento social das famílias beneficiárias no sentido de reverter tal exigência em real oportunidade de inserção social. Não obstante, no PBF não está prevista a realização de acompanhamento social das famílias por equipes multiprofissionais, o que requereria ações para além do controle estrito das contrapartidas. É indiscutível que ações dessa natureza contribuiriam em muito para o sucesso do Programa, a exemplo de outros programas nas áreas de assistência social e saúde que apostam no fortalecimento das relações de vínculo entre profissional e população beneficiária.

\section{Descentralização e intersetorialidade}

No que se refere à institucionalidade do Programa Bolsa-Família, um aspecto a ser destacado é que o desenho do Programa depende da ação coordenada dos três níveis de governo e de diversos setores governamentais e não governamentais. Assim sendo, a descentralização e a intersetorialidade, junto ao controle social, são os principais núcleos ordenadores do processo de implementação que se pretende levar a cabo.

A descentralização tem sido um dos eixos do processo recente de reformas das políticas sociais brasi- 
leiras, ainda que seu o ritmo e alcance deste processo tenham variado conforme cada área da política social. Diversos estudos (ARRETCHE, 2000; SOUZA; CARVALHO, 1999) têm salientado que a descentralização provocou um aumento da autonomia das instâncias subnacionais de governo, favoreceu a ampliação dos espaços de participação e a emergência de experiências inovadoras em relação aos programas sociais.

Ao mesmo tempo, reconhecem que as desigualdades existentes no Brasil se refletem também em profundas diferenças nas condições financeiras, políticas e administrativas de estados e municípios, afetando sua capacidade de resposta às necessidades da população e aos novos papéis que lhes são atribuídos. Nesse sentido, talvez um dos maiores obstáculos seja a persistência de uma lógica de relacionamento intergovernamental fortemente competitiva, em detrimento de interações cooperativas.

No caso do Programa Bolsa Família, o Governo Federal tem dado ênfase à gestão compartilhada envolvendo os três níveis governamentais. A assinatura de termos de cooperação entre o MDS, estados e municípios para a implantação do Programa e a possibilidade de complementação, por parte dos entes subnacionais, dos recursos financeiros transferidos às famílias beneficiárias são aspectos destacados pelos formuladores do PBF como estratégias importantes de incentivo à adesão ao Programa e à cooperação intergovernamental.

Recentemente, o Governo Federal lançou um índice de qualidade da gestão descentralizada do Programa Bolsa Família. O Índice de Gestão Descentralizada (IGD) varia de 0 a 1 e é composto pelas variáveis relativas às informações sobre freqüência escolar, acompanhamento dos beneficiários nos postos de saúde, cadastramento correto e atualização cadastral. Cada uma das quatro variáveis representa $25 \%$ do IGD. Este índice pretende estabelecer um ranking das experiências de implementação do PBF no nível local, premiando aquelas bem-sucedidas e incentivando a gestão de qualidade através do repasse de recursos financeiros extras para as prefeituras que alcançarem desempenho acima de 0,4 do índice.

Ressalta-se que não estão previstos mecanismos sólidos de indução capazes de superar a tradição competitiva que marca a área da assistência social. Isso pode ser observado na ausência de normalização específica e também no fato de que a pactuação intergovernamental vem ocorrendo pari passu ao processo de implementação.

Decerto, o curso do processo de descentralização na área social apresenta ritmos diferenciados tanto no que se refere à transferência de responsabilidades para os estados e municípios quanto às diversas políticas sociais setoriais. Uma das conseqüências deste processo é que as áreas que mais avançaram em direção à descentralização se deparam hoje com limites estruturais da sociedade brasileira que, apesar das conquistas realizadas, necessitam de enfrentamento intersetorial, através da conformação de uma rede de proteção social.

Com efeito, a formulação de políticas sociais com esta concepção não foi a tônica da reforma pósconstituinte e só recentemente o desafio da intersetorialidade vem sendo tratado de forma mais concreta, ocupando lugar de destaque na agenda de debate da área social do Governo Federal.

Tendo como base a experiência de descentralização das políticas sociais, é possível supor que num país com estrutura federativa como o nosso, a ausência de indução e coordenação da implantação da intersetorialidade por parte dos níveis federal e estadual de governo podem ser fatores que contribuam para o insucesso da proposta que se quer implementar. Embora o Governo Federal tenha, até recentemente, privilegiado a indução do processo descentralizador, pode-se afirmar que a concepção presente no Programa Bolsa Família representa certa preocupação em dar um passo adiante no enfrentamento da fragmentação da intervenção do Estado na área social. Isso porque até hoje nenhum outro programa social foi tão dependente da articulação intersetorial e, portanto, das capacidades institucionais e de diálogo político entre os entes da federação e entre os diferentes setores responsáveis pelo desenvolvimento das políticas sociais.

Também aqui falta clareza na definição das estratégias de implementação da intersetorialidade, assim como são frágeis os mecanismos de indução por parte do Governo Federal. Em realidade, ainda não foram construídos canais de diálogo eficientes entre os diferentes setores de governo nas três esferas político-administrativas. O desenvolvimento concreto da intersetorialidade ainda se encontra dependente da iniciativa do nível local, o que não é suficiente para sustentar experiências exitosas nessa área.

Andrade (2006) alerta que a tarefa de promover a intersetorialidade é bastante audaciosa e passa necessariamente pela construção criativa de um novo objeto de intervenção comum aos diferentes setores do Estado que lidam com a questão social. Está claro, assim, que o ponto forte da proposta de intersetorialidade é a possibilidade de construir uma visão de complexidade dos problemas, tendo como requisito o aporte de diferentes acúmulos setoriais, superando as propostas que se traduzem na mera sobreposição de ações setoriais.

\section{Controle social e mecanismos de participação social}

O controle social é possivelmente uma das facetas mais frágeis do PBF. Essa fragilidade ficou 
mais exposta após as diversas denúncias, veiculadas na mídia, sobre os casos de corrupção no processo de cadastramento único em diversos municípios brasileiros.

A fase inicial de implantação do PBF é marcada por um vazio quanto à normalização das ações de controle social. Naquela ocasião, havia uma indicação geral de que o controle social deveria ser realizado no âmbito local, através de um conselho ou comitê instalado pelo Poder Público Municipal, mas não se definia qual seria esta instância nem tampouco o seu papel com relação ao Programa.

A definição legal das instâncias responsáveis pelo acompanhamento do PBF só ocorreu pouco mais de um ano após sua implantação (com a publicação do Decreto de regulamentação do PBF e da Portaria 660 em setembro e novembro de 2004, respectivamente, encontradas em BRASIL, 2006), quando o PBF já atingia quase todos os municípios do país e cerca de 8 milhões de famílias.

O Decreto que regulamenta o Programa definia que o controle social em âmbito local deveria ser feito por um conselho formalmente constituído

\section{É certo que a instituciona-}

lização do controle social se

constitui um desafio não só

para o PBF, mas para as políti-

cas públicas de forma geral,

haja vista a fragilidade de

mobilização social e a pouca

tradição democrática do poder

público. pelo município ou mesmo por uma instância já existente, desde que fosse respeitada a paridade entre governo e sociedade civil, incluindo a representação dos beneficiários, e que tivesse dentre seus conselheiros, representantes das áreas de educação, saúde, assistência social, segurança alimentar e nutricional, da criança e do adolescente. Este conselho deveria ter caráter deliberativo e intersetorial, tendo como principais atribuições o acompanhamento, avaliação e fiscalização da execução do Programa no âmbito municipal.

Contudo, dada a urgência em implantar mecanismos de controle social do PBF, o MDS atribuiu, temporariamente, esse controle aos Comitês Gestores do Programa Fome Zero e aos Conselhos Municipais de Assistência Social, até que os conselhos previstos na legislação fossem constituídos.

Outro aspecto que merece destaque nesse aparato legal é a busca de maior transparência ao processo e responsabilização dos diferentes atores envolvidos, através da exigência de indicação, pelo nível local, do gestor municipal do PBF e do conselho de política pública que formalmente responderá pelo acompanhamento do Programa.

Somente em maio de 2005 é que se têm definições mais detalhadas sobre o controle social do PBF. Ao definir os procedimentos de adesão ao Bolsa Família, to das condicionalidades. Chama atenção o risco de se confundirem as funções de controle social com aquelas que caberiam aos gestores do PBF, o que pode estar associado a uma tendência a co-responsabilizar a sociedade civil organizada pelos rumos do Programa.

Ao mesmo tempo, tais atribuições exigem propostas potentes de formação de conselheiros, visto que, além de tratar-se de um programa social com mecanismos de gestão altamente complexos, apresenta muitas inovações em termos de sua estrutura operacional. Todavia, a questão da capacitação é uma preocupação ainda não suficientemente clara no desenho do Programa.

É certo que a institucionalização do controle social se constitui um desafio não só para o PBF, mas para as políticas públicas de forma geral, haja vista a fragilidade de mobilização social e a pouca tradição democrática do poder público. No caso do PBF, esses desafios se revestem de uma maior complexidade, considerando a necessidade de incorporar, também no controle social, a pactuação intersetorial.

\section{Considerações finais}

Este artigo traça uma análise da concepção do Programa Bolsa Família, principal intervenção do 
governo Lula no campo da política social, indicando alguns pontos importantes para a compreensão das potencialidades e limites do desenho do Programa.

No que diz respeito ao foco, vê-se que a combinação do critério único de renda monetária com a definição de uma linha de pobreza muito baixa resulta, em última instância, na restrição do potencial de inclusão social do Programa. Desse modo, corre-se o risco de não atingir os segmentos sociais que enfrentam situações diversas de vulnerabilidade que de maneira alguma pode ser reduzida à renda.

Um aspecto ressaltado como inovador na legislação e documentos oficiais do PBF é o foco na família. Porém, um estudo mais acurado da concepção do Programa reitera antigas preocupações em que ainda persiste a priorização de 'clientelas' tradicionais das políticas sociais, ou seja, crianças, adolescentes, gestantes e nutrizes. Se é certo, por um lado, que esses segmentos tendem a ser especialmente vulneráveis, por outro lado, não deixa de ser preocupante a pouquíssima ênfase dada a medidas voltadas à geração de emprego e renda que, associadas a estratégias socioeducativas junto às famílias, poderiam contribuir para romper com o ciclo de reprodução da pobreza.

A exigência de contrapartidas é talvez uma das novidades mais importantes no projeto do Bolsa $\mathrm{Fa}$ mília e, ao mesmo tempo, uma polêmica central do Programa. Muitos questionam a legitimidade da exigência de contrapartida, já que este benefício é um direito social e deve ter caráter incondicional. Por outro lado, no caso brasileiro, que apresenta muitas fragilidades no processo de constituição da seguridade social, é preciso, segundo os idealizadores do Programa, criar mecanismos que estimulem a inserção das famílias nos serviços de educação e saúde, tendo em vista a perspectiva de ruptura com o ciclo reprodutivo da pobreza.

Com efeito, no que tange às condicionalidades, pode-se dizer que, se por um lado tais exigências têm potencial para facilitar o acesso de camadas da população que dificilmente conseguiriam chegar aos serviços, por outro, coloca a dúvida sobre a capacidade de os serviços de educação e saúde absorverem adequadamente o aumento de demanda resultante da implementação do Programa. O mais grave é que estamos diante de uma situação em que se questionam as condições e a capacidade mesma dos municípios de ofertarem o que de mais básico está previsto no elenco de direitos sociais, isto é, as ações básicas de saúde e educação.

Da mesma forma, a perspectiva de punir as famílias que não cumprem as condicionalidades parece incompatível com os objetivos de promoção social do Programa. Assim, não se pode deixar de considerar as condições que as famílias dispõem para atender as requisições impostas, tendo em vista as dificuldades cotidianas de sobrevivência a que a maioria está exposta.
Com relação à autonomia das famílias, pode-se dizer que a ausência de indução de programas de geração de emprego e renda representa uma importante debilidade do PBF, uma vez que não há uma diretriz clara pautada na intersetorialidade e intergovernabilidade para atuar sobre as causas da precariedade de inserção da população adulta no circuito produtivo.

É necessário reconhecer ainda que o desenho do Programa indica uma multiplicidade de atores envolvidos em diferentes setores e níveis de governo, além da sociedade civil. Diante disto, cresce a complexidade da estrutura político-institucional.

No que se refere ao financiamento do Programa, constata-se que a própria lei de sua criação impõe constrangimentos à ampliação dos benefícios, visto que estes estão condicionados aos recursos financeiros existentes. Permanece o desafio de integrar as políticas econômica e social, rompendo com a assimetria histórica que submete a prioridade do gasto social aos ditames da economia.

Não obstante os limites de concepção do Programa, é necessário frisar que a retomada da pobreza como questão social a ser enfrentada pelo poder público indica uma perspectiva mais promissora para a conformação dos direitos sociais entre nós. Todavia, são muitos os desafios que ainda se interpõem nessa direção, tendo em vista a magnitude e complexidade da questão social e a histórica fragilidade do Estado brasileiro em dar respostas eficazes e efetivas.

\section{Referências}

ANDRADE, L. O. M. A saúde e o dilema da intersetorialidade. São Paulo: Hucitec, 2006.

ARRETCHE, M. Estado federativo e políticas sociais. Rio de Janeiro: Revan; São Paulo: FAPESP, 2000.

BRASIL. Ministério do Desenvolvimento Social e Combate à Fome. Programa Bolsa Familia. Legislação e Instruções. Disponível em <www.mds.gov.br/bolsafamilia/menu_ superior/legislação>. Acesso em: nov. 2006.

CARVALHO, M.C.B. A priorização da família na agenda da política social. In:__. (Org.) A família contemporânea em debate. São Paulo: Cortez/ EDUC, 1997, p. 11-21.

DRAIBE, S. A construção institucional da política brasileira de combate à pobreza: perfis, processos e agenda. Caderno de Pesquisa n.34. Campinas: NEPP/ UNICAMP, 1997.

et al. Programas de renda mínima para famílias carentes: levantamento das experiências e metodologia de avaliação. São Paulo: NEPP, 1998. Mimeografado. 
LAVINAS, L. Universalizando direitos. Revista Observatório de cidadania - relatório 2004: medos e privações - obstáculos à segurança humana. Rio de Janeiro: IBASE, março de 2004. p. 67-74.

et al. Combinando o compensatório e o redistributivo: o desafio das políticas sociais no Brasil. Texto para discussão n. 748. Rio de Janeiro: IPEA, jul. 2000, p.1-29.

MAGALHÃES, R. et al. Estudo da implementação do Programa Bolsa Família no estado do Rio de Janeiro. Relatório de Pesquisa CNPq. Rio de Janeiro: Fundação Osvaldo Cruz, 2005.

SEN, A. Desigualdade reexaminada. Rio de Janeiro: Record, 2001.

SOUZA, C.; CARVALHO, I. M. M. Reforma do Estado, descentralização e desigualdades. Lua Nova 48, 1999. p. 187-212.

TOWNSEND, P. The International Analisis of Poverty. New York: Harvester Wheatsheaf, 1993.

\section{Nota}

1 Durante os meses de setembro, outubro e novembro de 2005, várias reportagens veiculadas nos diversos meios de comunicação denunciavam fraudes no processo de cadastramento, seleção, entrega de cartões e acompanhamento das condicionalidades estabelecidas pelo PBF. Tais denúncias tiveram repercussões importantes na sociedade civil e no Governo Federal.

\section{Mônica de Castro Maia Senna}

Doutora em Ciências - Saúde Pública, pela Escola Nacional de Saúde Pública Sergio Arouca (ENSP) da Fundação Oswaldo Cruz (Fiocruz)

Assistente Social

Professora da Escola de Serviço Social da Univ. Federal Fluminense (UFF)

\section{Giselle Lavinas Monnerat}

Assistente Social, doutoranda na Escola Nacional de Saúde Pública Sergio Arouca (ENSP da FIOCRUZ) Professora da Fac. de Serviço Social da Univ. do Estado do Rio de Janeiro (UERJ)

\section{Vanessa Schottz}

Assessora do Prog. Direito à Segurança Alimentar e Agroecologia da Federação de Órgãos para Assistência Social e Educacional (FASE).

Nutricionista, Mestre em Saúde Pública pela ENSP Sergio Arouca da FIOCRUZ

\section{Rosana Magalhães}

Doutora em Medicina Social pelo Inst. de Medicina Social da UERJ

Pesquisadora da ENSP Sergio Arouca da FIOCRUZ Nutricionista, Mestre em Saúde Pública

\section{Luciene Burlandy}

Mestre e Doutora em Ciências - Saúde Pública pela ENSP Sergio Arouca da FIOCRUZ

Nutricionista, Professora da Faculdade de Nutrição da UFF

Universidade Federal Fluminense

Escola de Serviço Social

Campus do Gragoatá - Bloco E

São Domingos

Niterói - Rio de Janeiro

CEP: 24210-350 